\title{
The effects of ICT ownership on hospital performance in the Cameroonian context
}

\author{
KUTCHE TAMGHE Chevalier de Dieu, PhD, \\ Pan African Institute of Development, PO box 35527, Yaoundé-Cameroon \\ * E-mail of the corresponding author: Kutchevalier2002@yahoo.fr \\ NGAE Denis, PhD Student \\ Université of Madison, USA \\ Email: denisngae@yahoo.fr \\ ESSOMME Innocent, $\mathrm{PhD}$ \\ Université of Dschang, Cameroon \\ Email: essommeinnocent@yahoo.fr
}

\begin{abstract}
This study aims to research the effects of the ownership of ICT on hospital performance in the Cameroonian context. To achieve this objective, data from a field survey of a valid random sample of 479 employees from first and second category hospitals in Cameroon are subjected to descriptive and econometric analyzes. The results obtained reveal that the level of ownership of ICT by hospital staff is very average and has an impact on hospital performance. Indeed, the inferential analyzes performed using simple regression showed a positive and significant effect of the perceived ease of use of ICT, the perceived usefulness and cognitive absorption on hospital performance. These results, discussed from the perspective of Berbain and Minvielle (2001), Li, Benton and Leong (2002), Mukuna (2016) and Picard (2007) suggest acting on the determinants of ICT ownership, which are: training, raising awareness and improving the working conditions of hospital staff if we want to improve their ability to use and their enthusiasm for this use of ICT. this would improve staff satisfaction, patient satisfaction and the quality of clinical services.
\end{abstract}

Keywords: ICT ownership, Perceived usefulness, Perceived usability, Cognitive absorption, Hospital performance.

DOI: $10.7176 / \mathrm{IKM} / 10-3-05$

Publication date: April $30^{\text {th }} 2020$

\section{Introduction}

Since 2009, public hospitals in Cameroon have made changes in their internal and external operating environment, through the introduction of ICT in daily operations after several years of hesitation due to insufficient funding from the government (Ndongo \& al. 2010). One of these changes relates to the adoption and use of medical technologies in various aspects of hospital management, particularly hospital information systems (HIS). These are integrated information support systems (medical sensors, scanners, expert systems, management of patent registration) set up in most urban hospitals, in order to integrate and provide all patients, rapid information regarding the operation of the services offered, the clinic, accessories, legal and financial and other administrative matters (Jouët., 2010).

In this context, several public and private hospitals located in Cameroon have developed partnerships with university institutions and large hospitals in foreign countries, in order to deploy ICT tools and applications for health services, in particular isolated hospital information systems. and not integrated, specific to care units, in order to ensure the administrative and medical management of these units. These systems should make it possible in particular to: improve the management and processing of clinical information produced within the maternity unit; the management of essential medicines and medical consumables as well as for accounting; 
patient and antiretroviral management; management of the blood bank; queue management and biometrics (Ndongo \& al. 2010).

However, the expected impact of ICT on hospital health systems remains mixed globally (Millerand, 2008). The integration of these innovations in this hospital environment does not seem to provoke the desired enthusiasm, despite the efforts made by governments in the implementation of these Bagayoko projects (2010). The author reveals that some projects were even abandoned immediately after their implementation, others face sustainability problems and lack of enthusiasm in use while others experience under-exploitation installed functions. The results of a 2015 study by Standish Group International of 50,000 software development projects around the world showed that the number of projects that failed between 2010 and 2015 varied between 17 and $22 \%$. This observation is similar to that established by Bediang \& al. (2017) who, after having shown that telecardiology was feasible and improved patient care in a hospital located in a remote area, revealed that telemedicine projects, in Africa in general and Cameroon in particular, are suffering the problem of sustainability.

With all of the above, the question that guides this research is whether the ownership of information and communication technologies (ICT) has an effect on hospital performance in the Cameroonian context. Thus, the objective of this research is to show the influence of the ownership of ICT on hospital performance in Cameroon. The rest of this article presents a selective review of the literature. Then, the research model is presented as well as the methodology. Finally, the results are analyzed and followed by a discussion accompanied by managerial recommendations.

\section{Review of the literature}

In this section, we will discuss a theoretical and empirical review on the relationship between ICT ownership and hospital performance.

\subsection{The concept of ICT ownership}

Using Basque (2005), Williams et al. (2016) consider ICT as a set of technologies based on IT, microelectronics, telecommunications, multimedia and audiovisual, which, when combined and interconnected, make it possible to search, store, process and to transmit information, in the form of data of various types and allow interactivity between people, and between people and machines.

For Trinquecoste and Bidan (2011), when we talk about the concept of ownership of a technology, it seems difficult to define a border between this concept and the notions of use and adoption. Thus, Breton and Proulx (2002, p. 255) consider usage as "a complex phenomenon which results in the action of a series of tangled mediations between human actors and technical devices". Usage then corresponds to what actors actually do with technical objects. It refers to the use of technology that can be identified and analyzed through specific practices and representations (Millerand, 2008). Within the framework of this study, the accent is put on what the users (hospital staff) do with ICT. The term of use will be considered according to the approach of Jouët (2000) who stressed that uses are often the extension of social practices already integrated into everyday life. For this author, from adoption to trivialization, the construction of use takes place in stages marked by disenchantment with technique, by a narrowing of uses in terms of initial expectations and frantic jobs in the phase of exploration, in short by its passage to the status of ordinary object which incorporates it into social practices.

As for the concept of adoption, Guesmi (2012) uses it to designate both the decision to use an ICT and its subsequent purchase. It is above all a matter of equipment which is the result of a choice generally made before any implementation. For Le Nagard-Assayag and Manceau (2005), the definition of the concept of adoption of an innovation for example varies according to the context. In the durable goods sector, adoption refers to the first purchase, regardless of its subsequent use. The authors point out in this context that with regard to frequent purchase products, repeat purchase is necessary to consider that the product has been adopted. Quoting Robertson (1971), Cheikho (2015) confirms this approach to the concept of adoption and notes that adoption refers to the use of a new product continuously and that it is a moral bond rather than a trial purchase. Lapointe (2003) goes further by emphasizing that the adoption of a new technology is a very broad concept, since it includes acceptance, testing, use and internalization of this technology. In this sense, adoption behavior refers to a continuum integrating the different stages of technology integration by an individual or an organization. In the 
works of Breton and Proulx (2002), adoption is considered to be the first phase of use, upstream of ownership through use. According to these authors, adoption often comes down to purchase and consumption, on the other hand, use refers to the simple use of a technique in a face-to-face situation with the tool. In this research, we will discuss the adoption of a technology along the lines of Cheikho, $(2015, \mathrm{p} .44)$, as a concept that encompasses "acceptance and actual use". Thus, in the context of this research, the definition adopted is that of Pelletier and Moreau (2008) according to which technological ownership is the combination of certain individual psychological factors and technical knowledge which promotes spontaneous recourse and creative adaptation of " a computer tool or application by individuals members of an organization and this, on a voluntary basis.

DeSanctis and Poole (1994) propose to use a reading grid which makes use of four dimensions of ownership: modes of ownership which are the direct use or not of the structures of technology, the fidelity of ownership which is the degree of fidelity to the spirit of technology, the orientation of instrumentalization which is the meaning assigned to technology and attitudes towards technology. Other authors have mobilized two perceptions influencing the intention and behavior of ICT use, namely: the perception of usefulness and the perception of ease of use (Agarwal and Prasad, 1997). These two dimensions were considered insufficient for Agarwal and Karahanna, 2000; Pelletier and Moreau, 2008) who recommend associating the dimension of cognitive absorption with it. Thus, these last three dimensions are used to express the ICT ownership variable in this study, namely: perceived utility, perceived ease of use and cognitive absorption.

Perceived usefulness is defined as the degree to which a person believes that using a system will improve their performance. Perception of ease of use refers to the degree to which a person believes that using a system will be effortless. As for cognitive absorption, it corresponds to a deep state of engagement when using a technology or a computer tool resulting from both individual and situational factors (Agarwal and Karahanna, 2000). According to the theory of reasoned action, the technology acceptance model postulates that the use of an information system is determined by behavioral intention. However, stipulates on the other hand that this intention is determined jointly by the attitude of the person towards the use of the system and the perception of utility. Thus, according to Davis, Bagozzi and Warshaw (1989), the general attitude of the individual towards the system is not the only thing that determines usage, but can be based on the impact it will have on his performance. Therefore, even if an employee does not like a system, he is likely to use it if he perceives it to improve his performance at work. Furthermore, the technology acceptance model stipulates a direct link between the perception of usefulness and the perception of ease of use.

Figure 1. Technology acceptance mode

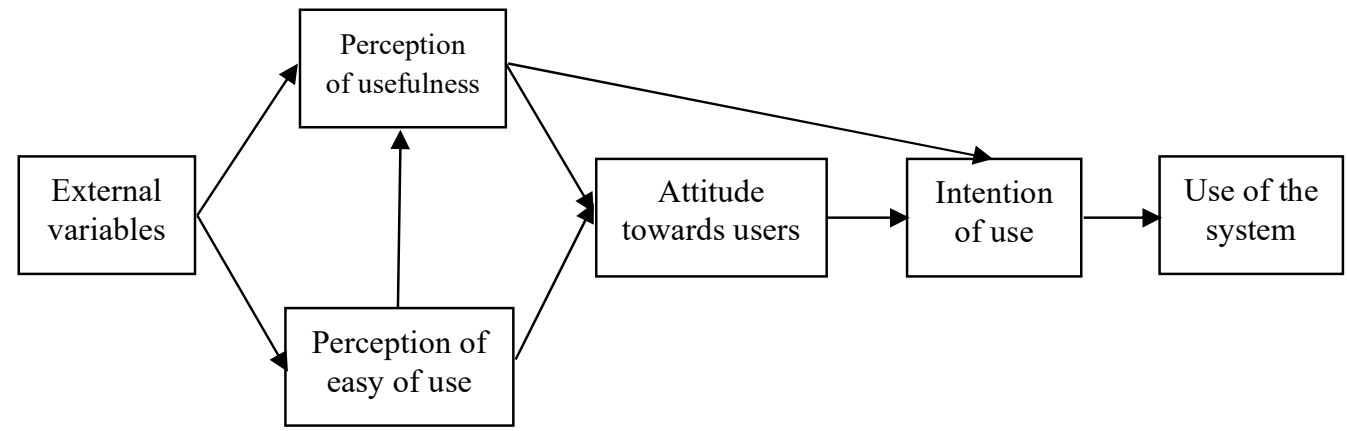

Source: Translated from the diagram of Davis, Bagozzi and Warshaw (1989)

According to these authors, the perception of ease of use would also significantly influence an individual's attitude, and this through two main mechanisms: self-efficacy and instrumentality. Indeed, according to the theory of Bandura (1986) cited by Pelletier and Moreau, 2008), the feeling of personal effectiveness with regard to technologies refers to the perception of an individual as to his current and future skills to use. these in the accomplishment of its task. The easier a system is to use, the more self-effective the user will be. Likewise, the ease of use of a tool would also give the user the feeling of having control over what he does (Lepper, 1985). Efficiency is one of the main factors underlying intrinsic motivation (Lepper, 1985) and this is what illustrates here the direct link between the perception of ease of use and attitude. Perceived ease of use can also be 
instrumental in improving performance. Indeed, the effort saved thanks to the ease of use, can be redistributed to accomplish more work with the same effort (Davis, Bagozzi and Warshaw, 1989). It is however interesting to note that the works used to validate their model, demonstrate that the link between the intention to use an information system and the perception of utility is stronger than with the perception of ease of use. So, according to this model, we can expect that the element that most influences a user is the perception of the usefulness of a tool.

Cognitive absorption refers to a deep state of engagement when using a technology or a computer tool resulting from both individual and situational factors Agarwal and Karahanna (2000). According to these authors, this deep state of engagement is revealed through five dimensions: temporal dissociation (loss of the notion of time), immersion or total concentration in a task, the intensity of pleasure, the feeling of interaction control as well as sensory and cognitive curiosity. Studies by Burton-Jones and Straub (2006) as well as by Qahri-Saremi et al. (2018) confirmed the results of research by Agarwal and Karahanna (2000) on information systems that consider the elements of pleasure, favorable emotional state and positive affective responses from the user of a one way or another, notably through the concepts of perceived utility and perceived ease of use.

\subsection{The concept of hospital performance}

The concept of performance management has entered the minds of all leaders of public and private organizations today. Kutche (2019) says of performance that it translates into three concomitant elements, namely efficiency, which measures the qualitative and quantitative degree of achievement of results; the efficiency which reflects the optimization of the resources mobilized to achieve the results and the relevance which translates the adequacy between the quantitative and qualitative means implemented to achieve the objectives set. However, it is not always easy to grasp this reality in the hospital sector subject to public service contingencies. For Le Pogam, Luangsay-Catelin and Notebaert (2009), if efficiency (cost-result ratio), productivity, medico-economic and financial performance seem generally favored in the conceptual economic model, other dimensions of performance hospital should be considered. Thus, several models of hospital performance exist throughout the literature with diversified measurement indicators.

The literature indicates two categories of models for assessing hospital performance: one-dimensional models of performance and multi-dimensional models. As part of our study we will focus on multidimensional models since they allow a better understanding of performance (kutche, 2019).

The "Performance Assessment Tool for Quality Improvement in Hospitals (PATH)" model is developed by WHO. In a 2008 WHO report, Smith, Mossialos and Papanicolas (2008) recommended a number of measures to improve the performance of health systems. Under the leadership of WHO, the "Performance Assessment Tool for Quality Improvement in Hospitals (PATH)" was developed, in order to help hospitals, collect data on their performance, to identify how comparisons are made. between hospitals, and to initiate a dynamic of quality improvement. They recommend the state of health provided by the health system, the ability to react to the preferences of the population, the financial protection offered by the system and the productivity of the latter. This performance management model allows hospitals to develop internal management dashboards.

The integrative model is based on Parsons' (1977) social system theory and allows adaptation to different contexts, including that of the hospital. This model assumes that for an organization to be efficient, in this case the hospital, it must maintain four functions: i) the function of adaptation to the environment, in terms of acquiring the resources necessary for maintenance and development of activities in order to meet the needs of the population, to improve its attractiveness and to mobilize the community and in terms of capacity to transform itself by adapting to changes, whether technological, demographic, political or social; ii) the function of achieving goals, in terms of improving the state of health of the population, effectiveness, efficiency and satisfaction of the various interest groups; iii) the function of integrating internal processes to produce, in terms of volume of services produced, coordination, productivity and quality of care; and iv) the function of maintaining values, in terms of producing meaning, cohesion inside the hospital and motivation or on the contrary demotivation.

The quality and overall performance model of Donabedian (1985) has the advantage of giving different dimensions to performance, but focusing on the quality of care, which can be defined by technical quality, but 
also by interpersonal quality between the caregiver and the neat. The author proposes four levels of evaluation: the quality of care provided by the nursing staff (evaluated from its technical and relational angles), the quality of the patient's reception infrastructure, the benefit provided to patients and their families. and the quality of the care service at the level of a territory (accessibility, continuity, coordination). This analysis highlights the value of a comprehensive performance approach to quality of care and highlights the role of multiple stakeholders in the performance of the health system. However, this performance model remains focused solely on the care variable and does not take into account organizational (human, financial, material) and strategic data (multiplicity of stakeholder expectations in a context of budgetary restrictions and growth needs).

The model of global and integral evaluation of the performance of health services, or EGIPSS model (Sicotte et al., 1998) is inspired by Parsons' theory of social action (1977) establishes that any organization must accomplish four essential functions: achieving goals, adapting, producing and maintaining values. According to the author of this theory, these functions coexist at all times and in all human organizations. The performance of the organization would be closely linked with its capacity to maintain a balance between the dynamic tensions presented by the challenges associated with the relationships between each function and the others.

More specifically, several studies have highlighted various indicators for measuring the performance of health facilities. To help administrators understand the characteristics of top performing hospitals, Williams et al. (2016), for example, used data from the Society for Health Management Information Systems and the Center for Medicare and Medicaid to assess 1,039 hospitals. They used indicators of quality measurement, hospital readmission and mortality rate. In their study on the evaluation of the performance of social security hospitals through the PATH, Asefzadeh et al. (2018) prioritized the dimensions: safety, patient-centered, clinical effectiveness, responsible governance, staff and efficiency. According to the results of this study, only $20 \%$ of the indicators in the PATH framework are evaluated and these indicators are linked to clinical performance and the clinical efficiency of hospital operations.

Cinaroglu and Baser (2018) explored the relationship between effectiveness and health outcome indicators with regard to the level of development and geographic region of 81 provinces in Turkey using the PATH framework. In their study, the number of hospitals and doctors is used as an indicator of accessibility to health services, while the average length of stay and the number of surgical operations are used as indicators of use. Life expectancy and overall satisfaction with health services are determined as outcome measures.

For their part, Dewi and Santoso (2018) analyzed the performance of the installation of hospitalized patients at Tria Dipa hospital with the balanced dashboard model, by mobilizing the four (4) main perspectives of the dashboard, consisting of (1) a financial perspective, (2) the client perspective, (3) the perspective of internal processes, and (4) learning and growth perspective. The result showed that the three fundamental perspectives of the performance of the hospitalization unit of the Tria Dipa hospital are generally quite good. However, the learning and growth prospects showed that the employees were dissatisfied and maintained their retention.

More recently, to assess the effectiveness of hospitals, Hatefi and Haeri (2019) have combined the balanced scorecard to determine performance indicators in hospitals and data envelopment analysis to assess the efficiency score of hospitals. hospitals. The results of their study showed that the use of dashboard measures in four dimensions: customer, finance, internal processes, growth and innovation reflected the general strategic objectives of hospitals in the performance evaluation process. In addition, the application of BSC methods and data envelopment analysis provides a comprehensive tool for assessing hospital performance and helps decisionmakers to obtain more precise planning to increase the capacity of health services and save money. the resources.

As can be seen, two categories of indicators for measuring hospital performance have been identified in the literature. These are clinical indicators and non-clinical indicators. Among these indicators, three were chosen in this study: patient satisfaction, staff satisfaction and the quality of clinical services.

\subsection{Links between ICT ownership and hospital performance}

Picard (2007) has shown that ICT skills in health are an essential lever on which we must act, to allow the implementation of ICT tools and applications and ensure their proper use within health and medico-social structures. According to him, the considerable development of medical knowledge, which must be accompanied 
by immediate dissemination to professionals to better care for patients, requires an increasing use of information technology. The Jackson Hole Group in the United States also maintains that the solution to significantly improve the quality of care requires the exchange of medical information between professionals and patients.

In a study carried out in 2010, Falise-Mirat, Alain, Billebot and Le Gloan established a positive link between the ownership of ICT and hospital performance. In a study carried out in 2010, Falise-Mirat, Alain, Billebot and Le Gloan established a positive link between the ownership of ICT and hospital performance. The performance indicators used were: the quality of the service rendered to the population, the responsiveness of organizations and the equity of funding. They conclude their study by indicating that information and communication technologies (ICT) are the preferred instrument, with more major potential to support the transformation of the health system. However, they believe that despite its demonstrated impact on the quality of care and accessibility, this lever remains little used, no doubt because of the difficulty in understanding the economic scope of investments in ICT, in particular the complexity of the distribution gains generated.

From another point of view, Berbain and Minvielle (2001) have shown that although the use of ICT in care units is a key factor in improving the quality of patient care, several health stakeholders have reservations as to their real contribution in daily work. For these authors, apart from technical failures, it is the ease of use and the ability of ICT to provide a solution to the organization of care which are poorly perceived by health professionals. They therefore recommend, the implementation with healthcare professionals, training mechanisms, with a view to acquiring the skills necessary to use ICT tools and applications in their daily activities. Following in their footsteps, Mukuna (2016) has shown that the ownership of ICT has a positive impact on the performance of hospitals using ICT in their operations. According to this author, the adoption of a good data management system, the use of computers, telephones and adequate internet facilities contribute positively to the performance of hospitals.

In light of all this literature, the general hypothesis of this study is structured as follows: The ICT ownership has an effect on hospital performance in Cameroon. From this general hypothesis, three specific research hypotheses emerge, namely:

- H1: The perceived ease of use of ICT by hospital staff influences hospital performance in Cameroon (Davis, Bagozzi and Warshaw (1989).

- H2: The perceived usefulness of ICT by hospital staff has an effect on hospital performance in Cameroon (Agarwal et Prasad, 1997).

- H3: The cognitive absorption of ICT by staff is linked to hospital performance in Cameroon (Agarwal and Karahanna, 2000).

\section{Methodology}

In this part, we present the sampling method, the data collection method, the study variables and measuring instruments and finally the results analysis tools used in this study.

\subsection{Sample and data collection}

The methodological approach is based on quantitative research. The simple random sampling method is used. Data were collected through questionnaires designed on the Likert model with 5 intensity levels (from "strongly disagree (1) to strongly agree (5)). According to the inventory prepared by the MINSANTE within the framework of the development of the sectoral health strategy, the number of staff in 2018 was estimated at around 38,207 people including 25,183 in the public $(66 \%)$ and $13,024(34 \%)$ in the private sector. The minimum sample size was found using Survey Monkey 2019 software. The confidence level chosen is $95 \%$ and a margin of error of $5 \%$ as is usually practiced in studies in management sciences. The result gives a minimum size of 381 individuals. In the case of this study, a total of 540 questionnaires were distributed to 30 hospitals, including 13 public hospitals of the first and second category and assimilated ( 3 in Douala, 9 in Yaoundé and 1 in Sangmélima) and 17 private hospitals (1 in Sangmélima, 6 in Douala and 10 in Yaoundé). A return of 512 completed questionnaires was obtained, a rate of $94.81 \%$. The flat sorting made it possible to purify these questionnaires by rejecting those whose all questions were not answered as well as those whose certain pages were non-existent or illegible. The number of valid questionnaires finally selected is 479 , representing a 
satisfactory response rate of $88.70 \%$.

\subsection{Data processing methodology}

The frequency analysis and the hypothesis test are preceded by an analysis of the internal reliability and the quality of the measurement scales. The internal consistency is analyzed through the Cronbach's Alpha test $(\alpha)$ which largely determines the dimensionality analysis. This is done through the method of multiple correspondences factor analysis (AFCM), since the study variables used are essentially qualitative. For the Cronbach's Alpha coefficient, the minimum threshold of 0.6 was retained while for the quality analysis the axes whose average variance presented is greater than 50 were retained.

Frequency analysis is used to measure the level of ICT ownership by hospital staff as well as the level of hospital performance perceived by users and patients. The items with an average opinion greater than 3 , representing the undecided opinion on the Likert scale, will be considered to be insufficiently appropriate. The same procedure will be used to measure the level of hospital performance. Items with an average response frequency less than or equal to 3 on the Likert scale indicate a low level of performance while the means greater than 3 indicate a satisfactory level of performance. The inferential analysis will be done through simple linear regression.

\subsection{Study variables and measurement instruments}

To measure the perceived ease of use, a total of 5 items inspired by the scales of Melas et al. (2011), Tsoni (2015) and Ling (2017). The factorial structure after purification made it possible to retain the 4 items which capture $70.94 \%$ of the average of the total variance represented (Overall, I found that the SIH was easy to use to perform my task; The SIH is easy to operate / execute; My interaction with the SIH to execute my task was clear and understandable; Learning to use the SIH to execute my task was easy). The Cronbach's Alpha coefficient is meritorious $(\alpha=0.86)$.

The measure of perceived utility was done using 5 items inspired by the adjusted scale of Belanche et al. (2012), Tsoni (2015), Jung et al. (2008) and Alharbi and Drew (2014). The factor structure after purification shows that 4 items have satisfactory psychometric qualities and capture $69.55 \%$ of the average of the total variance represented. (Using the SIH to execute my task increased my productivity; The use of the SIH optimizes the accomplishment in my tasks; The use of the SIH improves my efficiency in my daily work; I found in the use of the SIH, a response to my professional needs). The internal consistency is very satisfactory with a meritorious Cronbach's Alpha coefficient $(\alpha=0.85)$.

The cognitive absorption scale is inspired by the work of Tsoni (2015) and Qahri-Saremi et al. (2018). Four items are retained as having sufficient psychometric qualities with an average of the total represented variance of $70.20 \%$ (When I use the HIS, I feel totally immersed in what I do; When I use SIH, I don't get distracted easily; When I use SIH, I feel completely absorbed by what I'm doing; When I use SIH, my attention doesn't turn away very easily). The internal consistency of the items on this measurement scale is indicated as a meritorious Cronbach's Alpha of 0.85 .

The measurement of hospital performance takes into account the 18 items recommended by Shaukat et al., (2013), Deniz et al. (2017) and Cleven et al. (2016). The factor analysis made it possible after three (3) iterations, to retain 8 items with sufficient psychometric qualities to express the overall hospital performance. These items capture $66.57 \%$ of the average of the total variance represented. (Our hospital has short waiting times; Our hospital has a short stay; Our patients feel sufficiently informed about their treatment process; Our patients appreciate the simple processes / procedures and the short wait times in our hospital; Our hospital has a higher level of patient satisfaction; staff satisfaction is high; The level of organizational commitment of staff is high; I believe that I get the desired results). The internal reliability of the items on this scale is indicated by a meritorious Cronbach's Alpha of 0.92 . 
Table 1: AFCM summary of measurements of the different variables

\begin{tabular}{|l|c|c|c|}
\hline Variables & $\begin{array}{c}\text { Number of } \\
\text { items }\end{array}$ & $\begin{array}{c}\text { \% of average of total } \\
\text { variance represented }\end{array}$ & $\begin{array}{c}\text { Cronbach's } \\
\text { Alpha }\end{array}$ \\
\hline Perceived usability & 4 & 70,94 & 0,86 \\
\hline Perceived usefulness & 4 & 69,55 & 0,85 \\
\hline Cognitive absorption & 4 & 70,5 & 0,85 \\
\hline Hospital performance & 8 & 66,57 & 0,92 \\
\hline
\end{tabular}

Source : Autors

\section{Results}

The results of the data analysis highlight the descriptive analysis and the econometric analysis.

\subsection{Testing the level of ICT ownership and the perceived performance level}

The descriptive analyzes indicate that, in general, the level of ownership of ICT in the hospital structures concerned by the study is average as is the level of hospital performance. Indeed, the observation of Table 2 shows that on the Likert scale with 5 modalities ranging from strongly disagree to totally agree, the frequency of responses is 3.81 for ease of perceived usage with a standard deviation of 0.474 . Perceived utility has an average frequency of 3.58 and a standard deviation of 0.644 while cognitive absorption has an average frequency of 3.70 and the standard deviation of 0.580 . Hospital performance indicates an average frequency of 3.75 and standard deviation of 0.602 . This relatively average level of ownership of ICTs in hospitals in Cameroon seems to reflect weaknesses which have moreover been noted in the problematic and which tend to demonstrate in the opinion of Ndongo et al. (2010) that the ownership of ICT in the hospital sector still faces numerous contingencies which can be human, technological, economic, financial and managerial. The level of hospital performance is also average and seems to reflect a level of satisfaction of staff and patients as well as a clinical quality still insufficient.

\subsection{Results of the Inferential Analysis}

Simple linear regression is used to test the link between each aspect of ICT ownership and hospital performance. With regard to the analysis of the influence of the perceived ease of use on hospital performance, Table 3 of the model summaries indicates a coefficient of determination $\mathrm{R}^{2}$ of 0.43 , which is a contribution to the explanation of the variability $43 \%$ work stress. The $\mathrm{F}$ change is very significant with $\mathrm{p}$-value $\leqslant 0.01$. Based on these different results, the hypothesis that ease of use influences hospital performance is verified.

Table 2 : Model Summary of perceived ease of use regression on Hospital performance

Model Summary ${ }^{b}$

\begin{tabular}{|c|c|c|c|c|c|c|c|c|c|c|}
\hline \multirow[b]{2}{*}{ Model } & \multirow[b]{2}{*}{$\mathrm{R}$} & \multirow{2}{*}{$\begin{array}{c}\mathrm{R} \\
\text { Square }\end{array}$} & \multirow{2}{*}{$\begin{array}{l}\text { Adjusted } \\
\text { R square }\end{array}$} & \multirow{2}{*}{$\begin{array}{l}\text { Std Error of the } \\
\text { Estimate }\end{array}$} & \multicolumn{5}{|c|}{ Change Statistiques } & \multirow{2}{*}{$\begin{array}{l}\text { Durbin- } \\
\text { Watson }\end{array}$} \\
\hline & & & & & $\begin{array}{c}\text { R Square } \\
\text { Change }\end{array}$ & F Change & $\mathrm{d} 11$ & $\mathrm{~d} 12$ & $\begin{array}{l}\text { Sig. F } \\
\text { Change }\end{array}$ & \\
\hline 1 &, $656^{a}$ & ,430 & ,429 & ,45548 & ,430 & 360,042 & 1 & 477 &, 000 & 2,274 \\
\hline
\end{tabular}

a. Predictors : (Constante), Perceived easy of use

b. Dependant Variable : Hospital performance

Analysis of the regression model of perceived utility on hospital performance (Table 4) reveals a coefficient of determination $\mathrm{R}^{2}$ of 0.45 . this reflects a contribution of perceived utility to the explanation of variability in hospital performance of $45 \%$. The $\mathrm{F}$ change is significant with $\mathrm{p}$-value $\leqslant 0.01$. Based on these results, the hypothesis that perceived utility has an effect on hospital performance is verified. 
Table 3: Model Summary of perceived utility on Hospital performance

\begin{tabular}{|c|c|c|c|c|c|c|c|c|c|c|}
\hline & & & & & \multicolumn{5}{|c|}{ Change Statistiques } & Dodel Summary \\
Dodel & $\mathrm{R}$ & $\begin{array}{c}\mathrm{R} \\
\text { Square }\end{array}$ & $\begin{array}{c}\text { Adjusted } \\
\text { R square }\end{array}$ & $\begin{array}{c}\text { Std Error of the } \\
\text { Estimate }\end{array}$ & $\begin{array}{c}\text { R Square } \\
\text { Change }\end{array}$ & F Change & $\mathrm{d} 11$ & $\mathrm{~d} 12$ & $\begin{array}{c}\text { Sig. F } \\
\text { Change }\end{array}$ & Watson \\
\hline 1 &, $676^{\mathrm{a}}$ &, 457 &, 456 &, 44468 &, 457 & 401,197 & 1 & 477 &, 000 & 1,794 \\
\hline
\end{tabular}

a. Predictors : (Constante), Perceived utility

b. Dependant Variable : Hospital performance

Finally, the link between cognitive absorption and hospital performance is expressed in Table 5. This indicates a coefficient of determination $\mathrm{R}^{2}$ of 0.77 , which is a contribution of cognitive absorption to the explanation of the variability of hospital performance of $71 \%$. The $\mathrm{F}$ change is very significant with $\mathrm{p}$-value $\leqslant 0.01$. Based on these different results, the hypothesis that cognitive absorption influences hospital performance is not verified.

Table 4: Model Summary of regression of cognitive absorption on Hospital performance

Model Summary

\begin{tabular}{|c|c|c|c|c|c|c|c|c|c|c|}
\hline \multirow[b]{2}{*}{ Model } & \multirow[b]{2}{*}{$\mathrm{R}$} & \multirow[b]{2}{*}{$\begin{array}{c}\mathrm{R} \\
\text { Square }\end{array}$} & \multirow[b]{2}{*}{$\begin{array}{l}\text { Adjusted } \\
\text { R square }\end{array}$} & \multirow[b]{2}{*}{$\begin{array}{c}\text { Std Error of the } \\
\text { Estimate }\end{array}$} & \multicolumn{5}{|c|}{ Change Statistiques } & \multirow{2}{*}{$\begin{array}{l}\text { Durbin- } \\
\text { Watson }\end{array}$} \\
\hline & & & & & $\begin{array}{l}\text { R Square } \\
\text { Change }\end{array}$ & F Change & $\mathrm{d} l 1$ & $\mathrm{~d} 12$ & $\begin{array}{l}\text { Sig. F } \\
\text { Change }\end{array}$ & \\
\hline 1 &, $878^{a}$ &, 771 &, 771 & ,28843 &, 771 & 1610,370 & 1 & 477 &, 000 & 1,746 \\
\hline
\end{tabular}

a. Predictors : (Constante), Cognitive absorption

b. Dependant Variable : Hospital performance

\section{Discussion}

Following the results of this study we will organize the discussion from two angles. On the one hand, at the level of descriptive analysis and, on the other hand at the level of inferential analysis.

\subsection{Discussion of the results of the descriptive analysis}

This study aimed to analyze the influence of ICT ownership on hospital performance in Cameroon. To achieve this, descriptive analyzes were carried out, showing that the level of ownership of ICT in hospital structures is insufficient, the average frequency being around 3. These conclusions are in line with those of Bagayoko (2010) who a study on ICT in hospitals in French-speaking Africa noted that their level of ownership is still very low and is limited to simple office automation in Burkina Faso and Cameroon.

These same observations also corroborate those revealed in the report by Ndongo et al (2010) entitled "Strengthening the Health Information System to accelerate the Viabilisation of the Health District" where, after a mid-term evaluation of the sectoral health strategy (SSS) 2001-2010 noted that the HIS in Cameroon is still inoperative, fragmented, not integrated and does not provide information on the health map on the needs and level of satisfaction of users. According to this report, the level of ownership of ICT as a whole is still very low because of human contingencies such as resistance to change ; financial and material contingencies and a perceived utility that is still weak for all decision-makers in the hospital sector. They recommend raising awareness and strengthening user training (user staff in particular and decision-making executives) in the use of ICT in all of Cameroon's health districts. However, it must be recognized that since 2010, there has been a great deal of progress in the generalization of the use of ICT in hospital structures in Cameroon, even if the question of their effectiveness continues to be mixed. 


\subsection{Discussion of the results of the inferential analysis}

The findings of this study show that perceived utility, perceived ease of use, and cognitive absorption have a positive and significant effect on hospital performance. Thus, the general assumption that the ownership of ICT has an effect on hospital performance is fully verified.

Overall, these conclusions are in line with other authors who have worked on the subject even though they are in different contexts. Li, Benton and Leong (2002) for example, collected data from 151 American community hospitals, with the aim of developing and testing a strategic operations management model that links long-term service choices, business decisions intermediate operations and hospital performance given the structural constraints of location, size and medical education status in these hospitals. The measurements carried out focused on the cost, quality and financial performance of a hospital by comparing performance data from competing hospitals in the same region, establishments of similar size or other hospital characteristics. They found that health performance is largely dependent on the ability of hospital staff to use the HIS, their acceptance and commitment to use it. To this end, they recommend awareness-raising and continuing education for the various players. Similarly, Picard (2007) has shown that ICT skills in health and ease of use by staff are an essential lever for improving hospital performance. According to him, the considerable development of medical knowledge, which must be accompanied by training and immediate dissemination to professionals to better care for patients, requires an increasing use of information technology. In the same vein, Berbain and Minvielle (2001) have shown that although the use of ICT in care units is a key factor in improving the quality of patient care, several health stakeholders have reservations as to their real contribution in daily work. For these authors, apart from technical failures, it is the ease of use and the ability of ICT to provide a solution to the organization of care which are poorly perceived by health professionals. They therefore recommend, the implementation with healthcare professionals, training mechanisms, with a view to acquiring the skills necessary to use ICT tools and applications in their daily activities.

In the same vein, Mukuna (f2016) showed that the guarantee of an accounting and information management system and the use of qualified personnel trained in the use of ICT have a positive impact on the performance of hospitals using ICT in their operations. In the same vein, Mukuna (2016) has shown that the guarantee of an accounting and information management system and the use of qualified personnel trained in the use of ICT have a positive impact on the performance of hospitals using ICT in their operations. According to this author, the adoption of a good data management system, the use of computers, telephones and adequate internet facilities contribute positively to the performance of hospitals.

\section{Conclusion}

This study made it possible to examine the effect of ICT ownership on hospital performance in Cameroon. Frequency analysis has shown that the level of ICT ownership in Cameroonian hospitals is still low. Similarly, the performance of hospitals due to the use of ICT remains mixed. The results of inferential analysis through simple linear regression show that perceived utility, cognitive absorption and perceived ease of use have a positive and significant effect on hospital performance.

This study enriches current knowledge on the links between ICT ownership and hospital performance, in a context where, concerning Africa in general and Cameroon in particular, the morbidity rate in hospitals remains very high and the quality health services questioned. These conclusions bring up to date the need to strengthen research on the subject, focusing in particular on the obstacles to the ownership of ICT in hospitals. If we can recognize that these obstacles are psychic through resistance to change, it should be noted that technological obstacles can sufficiently explain the weakness of ownership. To this end, the insufficiency of the energy supply which leads to permanent power cuts in Cameroon, the insufficiency of the training of the users who find the TIC quite inaccessible and of the decision makers who have not yet understood the good- founded investment in the SIH.

Despite the contributions of this study, it has a certain number of limits which deserve to be noted : we did not highlight in this study, the determinants of the ownership of ICT nor the control variables such as the 
geographical location hospitals surveyed. Likewise, the age and sex of users would be used as information to better understand the contingencies that determine the ownership and influence of ICT on hospital performance. However, these limits open avenues of research for future studies that could integrate mediating or moderating variables such as socio-demographic criteria.

\section{References}

Agarwal, R., \& Karahanna, E. (2000). Time flies when you're having fun : Cognitive absorption and beliefs about information technology usage. MIS quarterly, 665-694.

Agarwal, R. \& Prasad, J. (1997). The role of innovation characteristics and perceived voluntariness in the acceptance of information technologies. Decision sciences, 28(3), 557-582.

Alharbi, S. \& Drew, S. (2014). Using the technology acceptance model in understanding academics' behavioural intention to use learning management systems. International Journal of Advanced Computer Science and Applications, 5(1), 143-155.

Asefzadeh, S., Mamikhani, J. \& Janati Rad, E. (2018). Evaluation of the Performance of Selected Social Security Hospitals Using the PATH Model in 2016 (Doctoral dissertation, Qazvin University of Medical sciences).

Bagayoko, C.O. (2010). Mise en place d'un Système d'Information Hospitalier en Afrique francophone : Cinz@n, étude et validation du modèle au Mali. Thèse de doctorat, Université de la Méditérranée, 142p.

Bediang, G., Kamga, Y., Nganou-Gnindjio, C. N., Amadou, N. N., Hamadou, B., \& Amvene, S. N. O. (2017). Faisabilité et Apport de la Télécardiologie dans la Prise en Charge des Patients dans un Hôpital de District du Cameroun. Health sciences and diseases, 18(4), 63-68.

Belanche, D., Casaló, L. V., \& Flavián, C. (2012). Integrating trust and personal values into the Technology Acceptance Model : The case of e-government services adoption. Cuadernos de Economía y Dirección de la Empresa, 15(4), 192-204.

Berbain, X. \& Minvielle, E. (2001). L'informatique dans la gestion quotidienne des unités de soins : la barrière de l'apprentissage. Sciences sociales et santé, 19(3), 77-106.

Breton, P. et Proulx, S. (2002). Usages des technologies de l'information et de la communication. L'explosion de la communication à l'aube du XXIème siècle, 251-276.

Champagne, F., \& Université de Montréal. Groupe de recherche interdisciplinaire en santé. (2005). Un cadre d'évaluation de la performance des systèmes de services de santé : le modèle ÉGIPSS, Évaluation globale et intégrée de la performance des systèmes de santé : résumé du rapport technique. GRIS, Université de Montréal.

Cheikho, A. (2015). L'adoption des innovations technologiques par les clients et son impact sur la relation clientCas de la banque mobile. Thèse de doctorat, Université de Nice.

Cinaroglu, S., \& Baser, O. (2018). Understanding the relationship between effectiveness and outcome indicators to improve quality in healthcare. Total Quality Management \& Business Excellence, 29(11-12), 1294-1311.

Cleven, A., Mettler, T., Rohner, P., \& Winter, R. (2016). Healthcare quality innovation and performance through process orientation : Evidence from general hospitals in Switzerland. Technological Forecasting and Social Change, 113, 386-395.

Davis F.D., Bagozzi, R.P., \& Warshaw P.R., (1989). User acceptance of computer technology: A comparison of two theoretical models. Management Science, N³5, pp. 982-1003.

DeSanctis, G., \& Poole, M. S. (1994). Capturing the complexity in advanced technology use : Adaptive structuration theory. Organization science, 5(2), 121-147.

Dewi, N. F., \& Santoso, R. K. (2018). The performance analysis of inpatient installation at Tria Dipa Hospital with balanced scorecard, 2013-2015. KnE Social Sciences, 1566-1583.

Donabedian A 1985. The Methods and Findings of Quality Assessment and Monitoring : an Ilustrated Analysis. Health Administration Press, Ann Arbor, MI.

Donabedian, A. (2005). Evaluating the quality of medical care. The Milbank Quarterly, 83(4), 691-729.

Falise-Mirat, B., Alain, D., Billebot, M.-N. \& Le Gloan, C. (2010). TIC et performance des organisation de santé. Gestions hospitalieres. N ${ }^{\circ} 495,2010 / 04$, pages 245-249

Guesmi, S. (2012). Trajectoires d'adoption et d'appropriation de TIC issues du web en entreprise : une analyse empirique de la diffusion du web 2.0 en entreprise (Doctoral dissertation, Paris 11).

Hatefi, S. M., \& Haeri, A. (2019). Evaluating hospital performance using an integrated balanced scorecard and fuzzy data envelopment analysis. Journal of Health Management \& Informatics, 6(2), 66-76.

Jouët, J. (2000). Retour critique sur la sociologie des usages. Réseaux. Communication-Technologie-Société, $18(100), 487-521$.

Jung, M. L., Loria, K., \& Saha, R. M. P. (2008). E-Learning : Investigating University Students Acceptance of Technology. European Journal of Open, Distance and e-learning, 11(2), 1-9. 
Kutche, C.D. (2019). Pratiques de gestion des ressources humaines et performance sociale dans les établissements du secondaire public au Cameroun. Thèse de doctorat, IPD, 323p.

Lapointe, L. (2003). L'adoption de systèmes d'information cliniques par les médecins et les infirmières : Une étude des variables individuelles, socio-politiques et organisationnelles (French text).

Le Nagard, E., \& Manceau, D. (2005). Marketing des nouveaux produits : de la création au lancement. Dunod.

Le Pogam, M., Luangsay-Catelin, C. et Notebaert, J. (2009). La performance hospitalière : à la recherche d'un modèle multidimensionnel cohérent. Management \& Avenir, 25(5), 116-134. doi :10.3917/mav.025.0116.

Lepper, M. R. (1985). Microcomputers in education: Motivational and social issues. American psychologist, $40(1)$

Li, L. X., Benton, W. C., \& Leong, G. K. (2002). The impact of strategic operations management decisions on community hospital performance. Journal of Operations Management, 20(4), 389-408.

Ling, L. T. (2017). The impacts of system quality and information quality on mobile users' behavioral intentions to use trade show application systems in Hong Kong: The mediating effects of perceived ease of use and perceived usefulness (Doctoral dissertation, The University of Newcastle, Australia).

Malekzadeh, R., Mahmoodi, G., \& Abedi, G. (2019). Assessment of Hospital Performance using Balanced Scorecard Model and Program Chain Pattern.

Melas, C. D., Zampetakis, L. A., Dimopoulou, A., \& Moustakis, V. (2011). Modeling the acceptance of clinical information systems among hospital medical staff : an extended TAM model. Journal of biomedical informatics, 44(4), 553-564.

Millerand, F. (2008). Usages des NTIC : les approches de la diffusion, de l'innovation et de l'appropriation (1ère partie). Commposite, 2(1), 1-19.

Mukuna, N. (2016). The effect of ICT adoption on the performance of health sector in Kenya : a survey of hospitals in Nairobi county. International Journal of Technology and Systems, 1(2), 12-29.

Ndongo, J.S., Ongolo-Zogo, P., Yondo, D., Nkoa, F.C. \& Bonono-Momnougui, C.R. (2010). Renforcer le Système d'Information Sanitaire pour accélérer la Viabilisation du District de Santé. Yaoundé, Centre pour le Développement des Bonnes Pratiques en Santé.

Parsons, T. (1977). Social systems and the evolution of action theory.

Pelletier, C. \& Moreau, É. (2008). L'appropriation des technologies de l'Internet et ses facteurs critiques de succès : un défi de plus pour les PME ? Revue internationale PME : économie et gestion de la petite et moyenne entreprise, 21(2), 75-117.

Picard, R. (2007). Les impacts humains des changements organisationnels autour des TIC. Perspectives interdisciplinaires sur le travail et la santé, (9-2).

Qahri-Saremi, H., Mueller-Luckey, G., Robinson, R., Hadidi, R. \& Sattovia, S. (2018). Actualization of Electronic Health Records Affordances : An Empirical Investigation of Users' Personal and Behavioral Antecedents.

Rogers. (2003). Diffusion of innovations. New York : Free Press (5th edition).

Shaukat, S., Nawaz, M. S. \& Naz, S. (2013). Effects of innovation types on firm performance : An empirical study on Pakistan's manufacturing sector. Pakistan Journal of Commerce and Social Sciences (PJCSS), $7(2), 243-262$.

Trinquecoste, J. F. \& Bidan, M. (2011). Regards croisés sur le processus d'appropriation des Technologies de l'Information et de la Communication. Management Avenir, (5), 175-178.

Tsoni, C. (2015). Proposition d'une échelle de mesure psychométrique de l'appropriation individuelle d'un outil informatique. Systèmes d'Information et Management, 17(4),25p.

Williams, C., Asi, Y., Raffenaud, A., Bagwell, M. \& Zeini, I. (2016). The effect of information technology on hospital performance. Health care management science, 19(4), 338-346. 